\title{
Establishment of an environmental microbiological monitoring program in a mice barrier facility
}

\section{GERALDINE SCHLAPP, GABRIEL FERNÁNDEZ-GRAÑA, ANA PAULA ARÉVALO and MARTINA CRISPO}

Transgenic and Experimental Animal Unit, Institut Pasteur de Montevideo, Mataojo 2020, CP 11400, Montevideo, Uruguay

Manuscript received on January 12, 2018; accepted for publication on April 26, 2018

\begin{abstract}
Rodents used in biomedical research are maintained behind barriers to exclude microbial contaminants. Several check points have to be monitored to eliminate the potential of introducing adventitious agents into the facility. Microbiological monitoring of a mouse facility environment enables to evaluate the efficiency of sanitization and cleaning procedures, air quality, and technician good practices. At our SPF mouse facility, we implemented an environmental microbiological monitoring program based in sedimentation and swabbing, inexpensive and easy to use methods. The aim of this work was to evaluate the results and the efficiency of the monitoring program after seven years. The median for bacteria and fungi counts in the SPF sampled areas was $\leq 2 \mathrm{CFU} / 2 \mathrm{~h}$ for settle plates and $<1 \mathrm{CFU}$ per swabbing plate, satisfying the requirements for grade $\mathrm{C}$ of the EU-GMP, with some modifications. The environmental monitoring program was useful to detect early warning of problems and enabled us to define a safe range of microbiological counts. In addition, SPF status defined for our mice was maintained throughout this study, confirmed by our HM program. This work could encourage directors and technicians of other mouse facilities in Latin America and rest of the world to implement this kind of program.
\end{abstract}

Key words: environmental microbiological monitoring program, health monitoring, settle plates, SPF mice facility, swabbing.

\section{INTRODUCTION}

There is worldwide consensus in the scientific community that rodents used in modern biomedical research need to be free of infectious agents, since the presence of pathogens without clinical signs may interfere with research outcome and lead to misinterpreted results (Burkholder et al. 2012, Shek 2008). To this aim, rodents are maintained behind multiple barriers to exclude microbial contaminants.

Correspondence to: Martina Crispo

E-mail: crispo@pasteur.edu.uy
Because barriers can and do fail due to intrinsic shortcomings, equipment failure, or operator noncompliance with standard operating procedures, routine health monitoring (HM) is necessary to verify that animals meet established Specific Pathogen Free (SPF) specifications (Shek 2008). The importance of a well-established health surveillance program and a list of organisms to be excluded from the facility, i.e., a SPF list, become critical in rodent facilities management (Sztein et al. 2011).

In order to reduce or eliminate the potential of introducing an adventitious agent into the 
facility, critical control points that pose the highest biosecurity risk have to be monitored. In that sense, the entry of animals; the use of biomaterials (cells, parasites, viral stocks, purified proteins or antibodies); the cleaning, disinfection and sterilization processes; the housing and husbandry (food, water, air and bedding); and the personnel must be carefully controlled (Pritchett-Corning et al. 2010). Environmental microbiological monitoring of a mouse facility enables to evaluate the efficiency of sanitization and cleaning procedures, air quality, and technician good practices.

Environmental microbiological monitoring of controlled areas is usually performed using a routine program, which should consider: frequency of sampling, time of sampling (during or at the conclusion of operations), duration of sampling, sample size (surface area), specific sampling equipment and techniques (Sheraba et al. 2010). There are different known techniques to perform the environmental microbiological monitoring of controlled environments: contact plates (Malik et al. 2013), settle plates (Napoli et al. 2012), swabbing (Aycicek et al. 2006), active monitoring of a known air volume (Cobo et al. 2008) and ATPbased methods to detect the presence of live or dead organic material (Aycicek et al. 2006, Turner et al. 2010).

Although there are many publications reporting environmental microbiological monitoring of clean areas in food manufacturing, drug production (Sandle et al. 2014) and surgery theatres (Landrin et al. 2005, Napoli et al. 2012) few works focused in rodent barrier facilities (Sakuma et al. 2013, Turner et al. 2010). The main objective of this work is to evaluate the results and efficacy of an environmental microbiological monitoring program established at our SPF facility during a seven-year period. This program is based in sedimentation and swabbing which are the most simple and inexpensive methods among all the methods described above. One of the goals is to satisfy the requirements for a grade $\mathrm{C}$ or $\mathrm{D}$ for microorganism-based cleanliness of European Guidelines.

\section{MATERIALS AND METHODS}

\section{ANIMAL FACILITY}

The SPF animal facility has an area of $145.8 \mathrm{~m}^{2}$, divided in different rooms (Fig. 1). The walls are epoxy coated and the floors have integral cove bases. The first barrier is an anteroom where personnel wearing special disposable clothes have to get dressed with sterilized overall, mask and cap, special shoes and disposable gloves. Animal rooms are equipped with four racks of individually ventilated cages (IVC-Tecniplast, Milan, Italy; Alesco, São Paulo, Brazil) each, open tables and wall shelves. The facility has also a storage room; two laboratories for experimental procedures and embryo micromanipulations; and two corridors (clean and dirty). Personnel workflow is one-way only.

All the animals in the facility were housed in the IVC racks, with $40-60 \%$ relative humidity, $20 \pm 1{ }^{\circ} \mathrm{C}$ temperature, light:dark cycles of $14: 10$ h, autoclaved food (Labdiet 5K67, PMI Nutrition, IN, USA) and ad libitum filtrated and autoclaved water. The facility houses more than twenty mutant lines and several mouse strains. Direct entry of animals into the rooms is allowed when they come from recognized vendors. Instead, rederivation by embryo transfer is performed when animals come from research institutions with unknown health status.

Washing and sterilization area is next to the facility, where all the materials are washed with pressurized hot water and prepared to be sterilized in double-door autoclaves (Högner, Buenos Aires, Argentina). Sterilization parameters for (i) cages with wood chips, (ii) cage tops and lids and (iii) food are: number of vacuum cycles: 3 , sterilization temperature: $121^{\circ} \mathrm{C}$, sterilization time: 20 minutes. Drying time is different for each type 
of material: 85, 20 and 30 minutes for (i), (ii) and (iii), respectively. Sterilization parameters for water bottles are: number of vacuum cycles: 1 , sterilization temperature: $121^{\circ} \mathrm{C}$, sterilization time: 30 minutes, no drying cycle.

Ventilation in the SPF area is achieved by two injection/extraction air handling units. Fresh air that passes through a series of filters (flat, bag and HEPA filters, respectively) is injected into the facility at $800 \mathrm{~m}^{3} / \mathrm{h}$. Also, this air handler is equipped with two radiators (hot/cold water) to regulate the air temperature. Then, air is extracted from the facility passing through a flat and a carbon filter. All the facility rooms are maintained at positive pressure. The air is changed 12 times/h.

Cleaning and disinfection of the facility is performed once a week. Floors, door knobs, tables and shelves are disinfected weekly, walls every other week, and ceilings once a month, using 1.5\% Benzalkonium chloride (Droguería Industrial Uruguaya, Emilio Benzo S.A., Montevideo, Uruguay) alternating with Despadac $\AA$ (Laboratorios Calier, Barcelona, España).

\section{ENVIRONMENTAL MICROBIOLOGICAL MONITORING PROGRAM}

\section{Sampling methods}

The environmental microbiological monitoring was performed quarterly using sedimentation and swabbing methods as stated before. The assay was performed the same weekday (Mondays) throughout the sampling period, with no personnel working in any of the facility rooms. Complete cleaning of the animal facility was done on Fridays. Disposable $90 \mathrm{~mm}$ Petri dishes were prepared with Tryptone Soy Agar (TSA) and Sabouraud Dextrose Agar (SDA) (Oxoid Limited, Hampshire, United Kingdom) following manufacturer's instructions

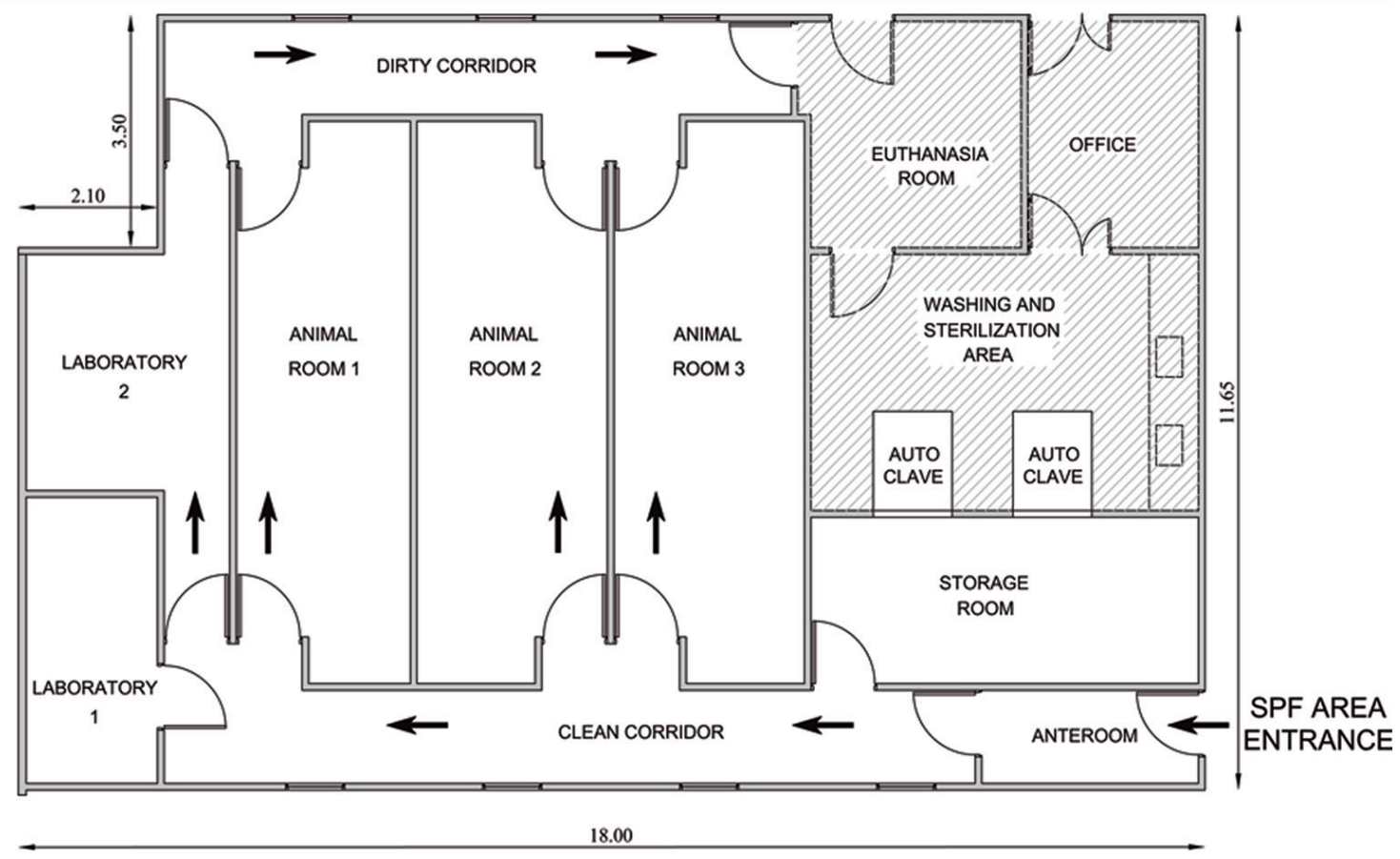

Figure 1 - Floor plan and workflow in the SPF facility. SPF area composed of three animal rooms: $1=$ breeding, $2=$ mouse colonies for transgenesis, 3 = experimentation; two laboratories: 1 = animal surgery and embryo manipulation, 2 = embryo micromanipulation; an anteroom, a storage room and two corridors (clean and dirty). Dirty materials go out by the dirty corridor only. Non-SPF area composed of a euthanasia room, a washing and sterilization area and an office (striped colored area). Black arrows indicate the workflow of personnel. Measures in metres. 
and used to detect viable aerobic bacteria and fungi, respectively. For sedimentation, dishes without lid were placed in selected checking points in the SPF area during a two-hour period. For swabbing protocol, sterile swabs were moistened in phosphate buffered saline (PBS), scrubbed against selected surfaces (approximately 0,2-0,3 $\mathrm{m}^{2}$, each) and finally rubbed against TSA-containing plates. Incubation was performed at $37^{\circ} \mathrm{C}$ for TSA plates and $25^{\circ} \mathrm{C}$ for SDA plates. Colony forming units (CFU) were counted and registered at $24 \mathrm{~h}$ for viable aerobic bacteria and $72 \mathrm{~h}$ for fungi. Bacteria growing in SDA plates were not considered. For both methods, the goal was to satisfy the requirements for grade $\mathrm{C}$ or $\mathrm{D}$ for microorganismbased cleanliness of the European Guidelines to Good Manufacturing Practice Medicinal Products for Human and Veterinary Use (EU GMP), Annex 1 (2003/94/EC 2008), with some modifications.

\section{Sampled areas}

A total of 14 checking points were sampled in each routine, one plate of each medium was used in the anteroom, both laboratories and the storage room, and two plates of each type of medium were used in areas larger than $15 \mathrm{~m}^{2}$ (animal rooms and both corridors). In swabbing method, floors, tables and knobs were tested. Positive control plates were sampled in non-restricted areas. For that, settle plates were placed in a corridor where air currents and personnel staff often circulates, and swabbing was performed in knobs and floors of the corridor. One plate of each medium without sampling was used as negative control.

\section{Health monitoring (HM) program}

Health status of the mouse colonies was monitored using in-house bred sentinels that were in contact with soiled bedding from other cages of the colonies for at least four months and subjected to HM testing. Analysis of serum was performed to detect mainly mouse pathogenic viruses; necropsy was performed to detect any gross organ abnormalities; search for ecto and endo-parasites were also done; and feces were collected to perform PCR Helicobacter analysis.

\section{Animals}

A total of 168 in-house bred adult BALB/cJ females were used as sentinels throughout the seven years of this study. Two HM cycles were performed per year, in which two animals housed together were used to monitor 56 IVCs, testing 2 IVC racks of each room every HM cycle. Every week during the cage changing, a sample of soiled bedding from four different cages from the same ventilated rack was added to sentinel clean cages (Mähler Convenor et al. 2014). After 4-6 months sentinels were subjected to HM testing. The bleeding and euthanasia performed in the mice to obtain samples for the HM were opportunely approved by the institutional Animal Ethics Committee, protocol number 003-16, in accordance to National Law 18.611 and international animal care guidelines (Guide for the Care and Use of Laboratory Animal) (NRC 1996) regarding laboratory animal's protocols.

\section{Analysis performed in sentinel animals}

Serum of sentinels was diluted in sterile PBS (1:5) after at least four months of starting the exposure, and analyzed by Multiplex Fluorescent Immunoassay (MFI) in IDEXX Bioresearch (Columbia, EEUU) against those agents that compose the specific pathogen free list of our mice facility: Mycoplasma pulmonis, Ectromelia virus, Epizootic Diarrhea of Infant Mice virus (EDIM), Lymphocytic Choriomeningitis Virus (LCMV), Mouse Hepatitis Virus (MHV), Mouse Norovirus (MNV), Mouse Parvovirus (MPV), Minute Virus of Mice (MVM), Pneumonia Virus of Mice (PVM), 
Reovirus 3 (REO3), Sendai virus, and Theiler's Murine Encephalomyelitis Virus (TMEV).

Necropsy and ecto and endoparasite examination were performed in-house. Fecal flotation and perianal tape-test were used to search for endoparasites, and fur swab for ectoparasites (Parkinson et al. 2011).

Sentinel feces were analyzed in-house by PCR against Helicobacter spp. Primers used were P008 (5'-TAGCTTGCTAGAAGTGGATT-3') and P009 (5'-ACCCTCTCAG-GCCGGATACC-3') which allowed detection of $H$. bilis, H. hepaticus, H. muridarum, and "H. rappini" (Bourgade et al. 2004). DNA extraction and PCR conditions were extracted from Truett et al. (Truett et al. 2000).

In the last year of this study period, samples were analyzed by IDEXX Bioresearch (Columbia, EEUU) against the annual agent panel recommended by Federation of European Laboratory Animal Science Associations (FELASA) (Mähler Convenor et al. 2014). For this purpose, sentinel serum and approximately $200 \mathrm{ul}$ of exhaust air dust (EAD) collected from ventilated racks, which is produced by accumulation of bedding and food dusty waste (sample collection was a personal assessment by Robert Livingston from IDEXX Bioresearch). Testing of EAD samples by PCR has been proposed as an alternative health monitoring strategy (Miller et al. 2016).

\section{Data analysis}

The number of CFU per area or surface for each monitoring day was plotted in scatter graphs. In the case of settle plates, the CFU obtained in areas larger than $15 \mathrm{~m}^{2}$ were averaged to obtain the corresponding value. In the case of swabbing plates, the number of CFU of different tested surfaces was averaged depending on the type of room. For each area or surface, the median of CFU was calculated and represented in the graphs. Statistical differences between CFU in different areas or surfaces were analyzed by Kruskal-Wallis test and then by Dunn's post test. Differences were considered statistically significant at $\mathrm{p}<0.05$. Analyses and graphs were produced using GraphPad Prism ${ }^{\circledR}$ (5.00).

\section{RESULTS}

\section{ENVIRONMENTAL MONITORING}

Data from 16 monitoring reports are presented. The number of CFU of viable aerobic bacteria per TSA sedimentation plate and CFU of viable aerobic fungi per SDA sedimentation plate are shown in Figures $2 \mathrm{a}$ and $2 \mathrm{~b}$, respectively (CFU are presented in tables SIa-b as Supplementary Material). Data showed non Gaussian distributions; therefore, the median for each type of room or surface was calculated and non parametrical analyses were performed. In all SPF rooms, the median for TSA and SDA plates was $\leq 2 \mathrm{CFU} / 2 \mathrm{~h}$. Results were very satisfactory considering that the recommended limits of microbial contamination in settle plates for grade $\mathrm{C}$ and $\mathrm{D}$ clean rooms is 50 and $100 \mathrm{CFU} / 4 \mathrm{~h}$, respectively. The number of $\mathrm{CFU}$ of viable aerobic bacteria per TSA swabbing plate is shown in figure 3 (CFU are presented in table SII as Supplementary Material). The median was $<1 \mathrm{CFU} /$ plate, therefore, results were acceptable according to the recommended limits of microbial contamination in contact plates for grade C and D clean rooms (25 and $50 \mathrm{CFU} /$ plate, respectively). The median for positive control plates was 82.5 and $41 \mathrm{CFU} / 2 \mathrm{~h}$ for TSA and SDA plates, respectively (figure 2); negative control plates showed satisfactory results $(<1 \mathrm{CFU} /$ plate, data not shown). As expected, CFU of positive control in both sedimentation and swabbing plates was significantly higher than CFU of all sampled areas and surfaces $(p<0.01)$. There were no statistical differences between $\mathrm{CFU}$ of tested areas or surfaces in both monitoring methods, except between Animal room tables and both Laboratory tables and Dirty corridor knobs. This result showed that Animal room tables are the 
(a)

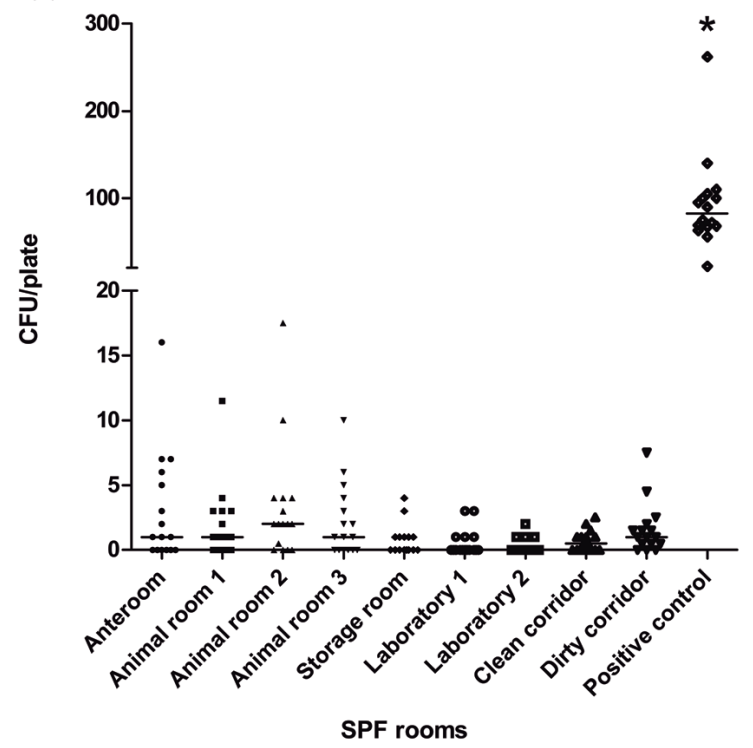

(b)

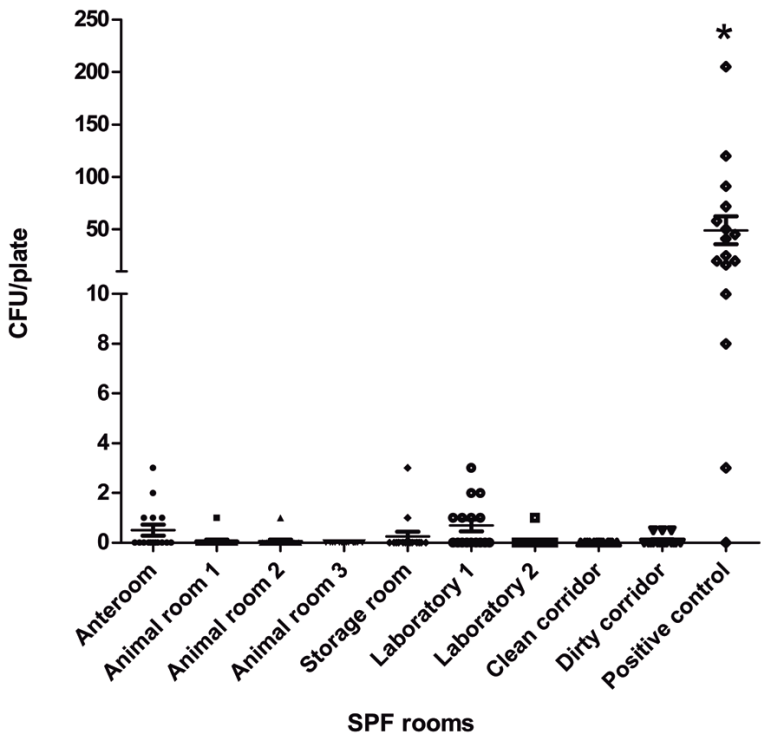

Figure 2 - Bacterial counts for TSA (a) and SDA (b) sedimentation plates. Each dot represents the CFU registered each monitoring day (16 time points). The median (horizontal bar) is indicated for each area. ${ }^{*} \mathrm{p}<0.01$ difference from the positive control group.

most contaminated surfaces in the facility and must be cleaned and disinfected more often.

\section{Health monitoring}

Throughout the study period, all the results for HM analyses performed in IDEXX Bioresearch showed no antibodies for any of the pathogens tested. Sentinel necropsies showed no gross pathology anomalies and no ecto or endo parasites were detected. Furthermore, when the annual FELASA exclusion list was analyzed in both serum and EAD samples, test results were negative except for EAD samples which were positive for Proteus mirabilis and Staphylococcus aureus, both opportunistic microorganisms that are not excluded in our SPF specifications.

\section{DISCUSSION}

It is well known that microbiological quality of experimental animals is critical, on one hand it can influence animal welfare and on the other, it can affect the validity and reproducibility of research data. Several infectious agents have been identified over the years that have either adverse effects on animal health and/or research outcome. For this reason, most mouse colonies are maintained in SPF barrier animal facilities, free of previously defined infectious agents (Burkholder et al. 2012). A barrier is a housing system that combines construction features, equipment, and operating methods to stabilize the enclosed environment in order to minimize the probability that pathogens or other undesirable organisms will contact or infect the enclosed animal population. Barriers may be provided at the facility, room, rack, and/or cage levels (Institute of Laboratory Animal Resources (U.S.). Committee on Infectious Diseases of Mice and Rats. 1991). Routine receipt of animals depends on regulations of each institution; most of them are permissive -allowing direct entry of mice into holding rooms- only when animals come from production areas of recognized vendors with a known high health status maintained for years. Instead, rederivation by embryo transfer is a common procedure performed when mice 


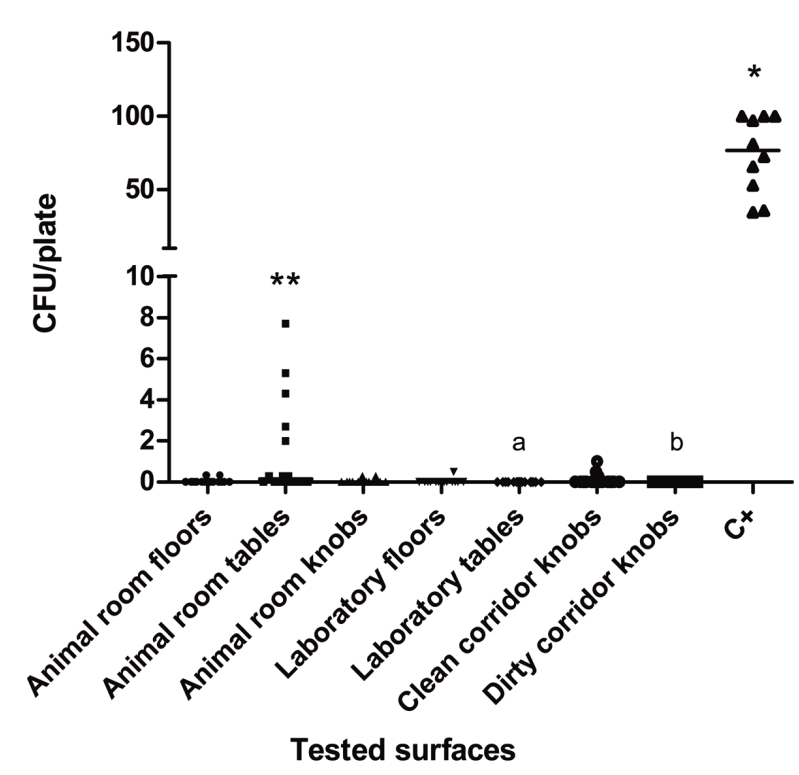

Figure 3 - Bacterial counts for TSA swabbing plates. Each dot represents the CFU registered each monitoring day (16 time points). The median (horizontal bar) is indicated for each type of surface and area. $* \mathrm{p}<0.01$ difference from the positive control group. $* * \mathrm{p}<0.05$ difference between Animal room tables and both Laboratory tables (a) and Dirty corridor knobs (b).

are introduced from research laboratories, which has proven to eliminate various viral agents, Helicobacter spp, and parasites (Sztein et al. 2011).

SPF status is generally monitored by exposing sentinel animals to dirty bedding of colony animals and testing the sentinel animals. Moreover, careful observation of mice in their home cage can provide a wealth of information about the health and welfare of the animals (Burkholder et al. 2012). Most infections do not lead to overt clinical signs but can influence the physiology of a laboratory animal (behaviour, growth rate, relative organ weight, immune response, among others). Silent infections are often activated by experimental procedures (stress, immunosuppression, toxic substances, tumours) or environmental influences (transportation, suboptimal humidity or temperature). Apparent or inapparent infections may confound scientific results, increase biological and experimental variability, and cause an increase in animal use. Contamination of biological materials such as transplantable tumours and other tissues can occur as a result of latent infections in animals. Such contamination may in turn infect new animals or interfere with the materials' use. Some infections in laboratory animals can also produce zoonoses (Mähler Convenor et al. 2014). For all these reasons, it is not only important to establish a laboratory animal HM program as an integrated part of any quality assurance system, but also to monitor the good performance of the husbandry and restriction elements included in the barrier system defined for each facility. The microbiological monitoring of an animal facility environment allows to control the efficacy of cleaning and disinfection procedures, air quality and technician good practices, some of the multiple key points of a barrier facility that must be controlled in order to prevent the entry of contaminant microbial agents.

Disinfection in animal facilities could be performed using a great variety of disinfectants, for instance sodium hypochlorite $(10 \%$ bleach $)$, a hydrogen peroxide-peracetic acid mixture, quaternary ammonium chloride compounds, among others (Turner et al. 2010). From the inception of our mice facility we have always used disinfectants in an alternated mode, using compounds that are active against different kind of microorganisms. We used to disinfect the facility with Virkon ${ }^{\circledR}$ S alternated with benzalkonium chloride and then changed to Despadac ${ }^{\circledR}$ alternated with the same quaternary ammonium. Virkon ${ }^{\circledR}$ and Despadac ${ }^{\circledR}$ are well known disinfectants commonly used in livestock and poultry establishments.

Barrier facilities are classified on the basis of operational criteria and the degree of security provided (ILAR). The use of personal protective equipment (PPE) elements, sterilized feed and drinking water, individually ventilated caging, restricted entry, are some of the husbandry restrictions that apply to standard barriers. Maintaining intact barriers and ultimately 
preserve the health of the mice requires great effort; therefore, it is critical that animal care technicians and researchers entering the facility and handling animals understand the importance of good practices to prevent pathogens from being introduced.

There are few publications reporting environmental microbiological monitoring of mouse facilities: one work focused on the use of particle counting by active methods in a University of Tokyo and the other on ATP-based methods in a University of New York (Sakuma et al. 2013, Turner et al. 2010). Since we searched for more affordable methods to perform in our facility, we established a program using standard microbial counting methods in which we already have some experience. Sedimentation or settle plates require no special equipment, are inexpensive and easy to use. Even though is possible to count CFU, the overall result has to be taken as a qualitative parameter since it cannot sample specific volumes of air. In our hands, the use of sedimentation method allowed to evaluate the quality of the air and proved early warning of problems. On the other hand we chose the swab-rinse method, originally developed to assess the bacterial contamination of eating utensils (Manheimer and Ybanez 1917). The application of swabbing in our program has been useful to evaluate the efficiency of our disinfection procedures and monitoring contamination of specific surfaces, allowing for instance to detect improper disinfection of a specific surface.

Considering that in the literature there are no recommended limits for environmental microbiological monitoring of laboratory mice facilities, our goal was to satisfy the requirements for a grade $\mathrm{C}$ or D microorganism-based cleanliness of EU GMP Annex 1. Some modifications were introduced in our environmental program: (i) the exposition time of sedimentation plates was set to 2 rather than $4 \mathrm{~h}$ as determined in GMP requirements, since $4 \mathrm{~h}$ was an extremely long period to restrict the entrance of researchers and technicians; (ii) the swabbing protocol was referenced to GMP recommendations for contact plates.

Regarding the overall results of our environmental program, the median for bacteria and fungi counts in our SPF facility throughout the study was $\leq 2$ CFU for both settle and swabbing plates, therefore, we assumed that the facility accomplished the requirements for 'Clean areas for carrying out less critical stages in the manufacture of sterile' (grade C and D rooms, EU GMP), although our monitoring program had a shorter exposition time comparing to the GMP limits. Very recently, we were able to perform an environmental classification of the SPF facility based in particle counting by a certifying company (Novatec Ingenieria) using standard methods. As a result, all the animal rooms were classified as class 7, ISO14644-1, which corresponds to Grade $\mathrm{C}$ clean room (at rest). Nevertheless, it is important to have in mind that a longer exposition time of sedimentation plates to fulfill GMP Grade C recommendations with absolute rigor could affect our initial assumption.

Health monitoring program throughout this study period has confirmed that our mice colonies are free of those microbial agents we test against, in serum and feces samples.

In the last years, the emergence of protocols based in exhaust air dust samples and dried blood spots allowed us to widen the list of excluded microorganisms at an affordable price.

In conclusion, after this environmental microbiological monitoring period, we were able to define a safe range of microbiological counts to be obtained in the environmental monitoring results of our facility. This monitoring program enabled us to detect early warning of problems related to cleaning procedures and failure of air conditioning equipments, for instance. Previous publications performed in USA and Japan are examples of procedures that could not be easily followed by Latin 
America facilities. Our results would encourage the staff of other Latin America research animal facilities to establish this kind of monitoring programs that are inexpensive and easy to carry out.

\section{ACKNOWLEDGMENTS}

The authors wish to thank Magdalena CárdenasRodríguez and Lucía Goyeneche for their assistance to perform microbiological sampling of the environment. Also, we thank Pablo Zunino for his contribution to data presentation and analysis. The authors declare that there is no conflict of interest.

\section{REFERENCES}

2003/94/EC. 2008. EU Guidelines to Good Manufacturing Practice Medicinal Products for Human and Veterinary Use. 4.

AYCICEK H, OGUZ U AND KARCI K. 2006. Comparison of results of ATP bioluminescence and traditional hygiene swabbing methods for the determination of surface cleanliness at a hospital kitchen. Int J Hyg Environ Health 209: 203-206.

BOURGADE F, MONTAGUTELLI X, BIGBEE C, WEISS A, RIGOTTIER-GOIS L, CONTI CJ AND BENAVIDES F. 2004. Simple duplex fecal PCR assay that allows identification of false-negative results in Helicobacter sp.infected mice. Comp Med 54: 528-532.

BURKHOLDER T, FOLTZ C, KARLSSON E, LINTON CG AND SMITH JM. 2012. Health Evaluation of Experimental Laboratory Mice. Curr Protoc Mouse Biol 2: $145-165$.

COBO F, GRELA D AND CONCHA A. 2008. Airborne particle monitoring in clean room environments for stem cell cultures. Biotechnol J 3: 43-52.

INSTITUTE OF LABORATORY ANIMAL RESOURCES (U.S.). COMMITTEE ON INFECTIOUS DISEASES OF MICE AND RATS. 1991. Infectious diseases of mice and rats, Washington, D.C.: National Academy Press.

LANDRIN A, BISSERY A AND KAC G. 2005. Monitoring air sampling in operating theatres: can particle counting replace microbiological sampling? J Hosp Infect 61: 2729.

MÄHLER CONVENOR M, BERARD M, FEINSTEIN R, GALLAGHER A, ILLGEN-WILCKE B, PRITCHETTCORNING K AND RASPA M. 2014. FELASA recommendations for the health monitoring of mouse, rat, hamster, guinea pig and rabbit colonies in breeding and experimental units. Lab Anim (NY) 48: 178-192.
MALIK DJ, PATEL KV, CLOKIE MR AND SHAMA G. 2013. On the difficulties of isolating Clostridium difficile from hospital environments. J Hosp Infect 84: 181-183.

MANHEIMER WA AND YBANEZ T. 1917. Observations and Experiments on Dish-Washing. Am J Public Health (NY) 7: 614-618.

MILLER M, RITTER B, ZORN J AND BRIELMEIER M. 2016. Exhaust Air Dust Monitoring is Superior to Soiled Bedding Sentinels for the Detection of Pasteurella pneumotropica in Individually Ventilated Cage Systems. J Am Assoc Lab Anim Sci 55: 775-781.

NAPOLI C, MARCOTRIGIANO V AND MONTAGNA MT. 2012. Air sampling procedures to evaluate microbial contamination: a comparison between active and passive methods in operating theatres. BMC Public Health 12: 594.

NRC. 1996. Guide for the care and use of laboratory animals, $7^{\text {th }}$ ed., Washington (DC): National Academies Press.

PARKINSON CM, O'BRIEN A, ALBERS TM, SIMON MA, CLIFFORD CB AND PRITCHETT-CORNING KR. 2011. Diagnosis of ecto- and endoparasites in laboratory rats and mice. J Vis Exp: e2767.

PRITCHETT-CORNING KR, SHEK WR, HENDERSON KS AND CLIFFORD CB. 2010. Companion Guide to Rodent Health Surveillance for Research Facilities, $2^{\text {nd }}$ ed., Charles River.

SAKUMA K, HAYASHI S, OTOKUNI K, MATSUMOTO I, MATSUOKA H AND SAITO M. 2013. Standard operating procedures for maintaining cleanliness in a novel compact facility for breeding SPF mice. J Am Assoc Lab Anim Sci 52: 717-724.

SANDLE T, LEAVY C, JINDAL H AND RHODES R. 2014. Application of rapid microbiological methods for the risk assessment of controlled biopharmaceutical environments. J Appl Microbiol 116: 1495-1505.

SHEK WR. 2008. Role of housing modalities on management and surveillance strategies for adventitious agents of rodents. ILAR J 49: 316-325.

SHERABA NS, YASSIN AS AND AMIN MA. 2010. Highthroughput molecular identification of Staphylococcus spp. isolated from a clean room facility in an environmental monitoring program. BMC Res Notes 3: 278.

SZTEIN J, KASTENMAYER R AND PERDUE K. 2011. Pathogen-free mouse rederivation by IVF, natural mating and hysterectomy. In: Pease S and Saunders T (Eds), Advanced protocols for animal transgenesis: an ISTT manual. $1^{\text {st }}$ ed., New York, USA: Springer, p. 615-642.

TRUETT GE, WALKER JA AND BAKER DG. 2000. Eradication of infection with Helicobacter spp. by use of neonatal transfer. Comp Med 50: 444-451.

TURNER DE, DAUGHERITY EK, ALTIER C AND MAURER KJ. 2010. Efficacy and limitations of an ATPbased monitoring system. J Am Assoc Lab Anim Sci 49: 190-195. 


\section{SUPPLEMENTARY MATERIAL}

TABLE SI - CFU registered each monitoring day in sedimentation plates. 1a: microbial counting in TSA plates at 24 hs of incubation; $1 \mathrm{~b}$ : microbial counting in SDA at $72 \mathrm{hs}$ of incubation. ND: not done. In areas larger than $15 \mathrm{~m} 2$ (Animals rooms and Corridors) the media between the two plates of each type of medium is shown.

TABLE SII - CFU registered each monitoring day in swabbing plates. For each type of surface, the media between the tested elements is presented. 